\title{
Ajustando o tom: confluências e divergências entre Nacional por subtração, de Roberto Schwarz, e Vanguarda e subdesenvolvimento, de Ferreira Gullar
}

\author{
Joseane Rücker ${ }^{*}$
}

\begin{abstract}
Resumo: Os problemas da cultura brasileira e de seu caráter ora inautêntico, ora postiço, têm preocupado há muito os intelectuais brasileiros. Esses, por sua vez, tentam, através de suas análises, corrigir posições ou construir formas de superar o sentimento de inferioridade que por tanto tempo fez-nos ver a metrópole como um espelho de nosso futuro. Superar antigas dependências e compreender os parâmetros que formam a arte brasileira, sobretudo respeitando as suas limitações, é entender que a melhor arte produzida por um país subdesenvolvido é aquela que parte de sua realidade específica, ou seja, do seu caráter particular para, assim, poder superar-se e transformar-se em seu contrário: a expressão estética universal. Para isso, o presente artigo estabelecerá diálogos entre Vanguarda e subdesenvolvimento, ensaio de 1969, de Ferreira Gullar, e Nacional por subtração, ensaio de 1986, de Roberto Schwarz.
\end{abstract}

Palavras-chave: Vanguarda; Nacionalismo; Subdesenvolvimento.

\begin{abstract}
The problems of Brazilian culture and its character, which is at times unauthentic and at times artificial, have been worrying Brazilian intellectuals for years. On their turn, they use analyses in order to try to correct positions or construct ways to overcome the feeling of inferiority that has made us take the metropolis as a mirror to our future for so long. In order to overcome old dependencies and set up the parameters that shape Brazilian art, respecting its limitations above all, it is necessary to understand that the best art produced in an underdeveloped country is the one that is generated from its specific reality, that is, from its particular character. Thus such art should be able to obtain the best of itself and turn into its contrary: the universal aesthetic expression. Therefore, this article will establish interactions between Vanguarda e subdesenvolvimento, an essay written in 1969 by Ferreira Gullar, and Nacional por subtração, another essay written in 1986 by Roberto Schwarz.
\end{abstract}

Keywords: Vanguard; Nationalism; Underdevelopment

Por muitas vezes, intrigava-me a relação que existe entre Nacional por subtração, de Roberto Schwarz, e Vanguarda e Subdesenvolvimento, de Ferreira Gullar, pois cria que os artigos possuíam pontos convergentes. Embora o primeiro seja de 1987, e o segundo de 1969, é sobretudo pelo ano de produção do artigo de Gullar e pelas querelas que envolvem a

\footnotetext{
* Joseane Rücker é professora de Língua Portuguesa e de Literatura Brasileira, em Porto Alegre, do Instituto Santa Luzia. É mestranda em Literatura Brasileira pela UFRGS
} 
consciência do subdesenvolvimento e a problematização do nacional que os trago para este trabalho.

A construção histórica de nosso país revela uma relação tensa entre cultura e imperialismo, pois, uma vez que nascemos dominados pelo outro, respiramos a necessidade de tentar superá-lo, de apagar as imagens que ele faz na construção de nossa identidade. Assim, é a partir da busca por um elemento nacional que procuraremos desvencilhar-nos dele, criando algo que seja só nosso e que não tenha, portanto, as marcas do colonizador.

Essa parece ter sido a tara mental brasileira que nos dominou por muitos séculos, desde os românticos até, pelos menos, os modernistas de São Paulo de 1922, pois falar em nacionalismo em tempos de pseudoglobalização não significa construir uma identidade, mas tentar não perdê-la, ou seja, reservá-la. Essa obsessão pelo nacionalismo só foi possível, nos explica Ferreira Gullar, porque fomos colonizados e porque tínhamos a preocupação de criar uma literatura ou arte nacional para concretizar a nossa libertação; não compreendíamos, é claro, que é da natureza da expressão estética superar essa procura.

A obsessão por libertar-se dos galhos do outro gerou na sociedade brasileira um descompasso, um caráter, de acordo com Schwarz, inautêntico e postiço, pois almejávamos, ao mesmo tempo, a libertação e o prestígio dos países que nos serviam de modelo. E será, portanto, a partir da estética romântica que vislumbraremos o primeiro movimento brasileiro que apresentará aspectos que visarão à construção de uma identidade autêntica. Gullar explica que: "O Indianismo, embora todo ele elaborado dentro do espírito romântico, é um esforço para superar inclusive a influência romântica recentemente importada" (GULLAR, 1978, p. 37). Essa idéia pode ser complementada pelas considerações de Antônio Cândido (1975, p. 113) que, por sua vez, afirma que os românticos objetivavam estabelecer um passado heróico e mitológico para a nossa civilização a partir da construção lendária e artística do índio.

José de Alencar possuiria uma crítica bem mais armada que suporíamos à primeira vista, pois abriria espaço para as discussões sobre universal versus particular, urbano versus regional. Antônio Cândido assegura em A formação da Literatura Brasileira que Peri ainda que apresente traços de comportamento que estariam mais próximos do cavalheiro medieval do que de um selvagem ou um nativo, não deveríamos desvalorizar a interpretação brasileira do mito do bon sauvage dos utopistas do século XVIII como uma tentativa de reconstrução da identidade. Ferreira Gullar também crê na importância do movimento indianista, pois este abriria caminhos mais tarde para o movimento sertanista. No entanto, o movimento sertanista condenaria o quadro litorâneo e o urbano como aquele em que transpareceria um falso Brasil. Para os sertanistas, o verdadeiro Brasil seria o do interior, o do sertão, pois estaria imune às 
influências externas, no caso, as européias. É importante ressaltar que todo esse quadro está unido às transformações políticas e econômicas da época. A expansão da economia cafeeira geraria, por exemplo, o crescimento da vida urbana, o desenvolvimento dos meios de transporte e das novas classes de funcionários públicos. Os artistas, deslumbrados com os arranha-céus e os aeroplanos, tornar-se-iam incapazes de refletir sobre tais modificações.

A preocupação com o caráter nacional da arte, para Gullar, em Argumentação contra a morte da arte, é relevante apenas para os autores ou artistas em geral de culturas dependentes, visto que os mesmos buscam autonomia, uma vida intelectual substantiva, como completaria Schwarz no artigo em estudo. Para este, a dependência cultural é resultado do subdesenvolvimento econômico, o que, por sua vez, provocaria no artista um sentimento de inferioridade. Assim, o artista, para livrar-se das sombras vai exigir de si apagar o outro. Como? A partir da não-imitação de seus modelos.

Esse anseio pelo prestígio europeu fez-nos escravos de suas imagens, pois não compreendíamos que essas imagens também nos refletiam. Schwarz chama esse processo de espelho reflexo, ou seja, não imitávamos o outro na literatura ou nas demais artes, principalmente em relação à estética romântica, porque dialogávamos com os artistas europeus ou refletíamos sobre suas estéticas, mas, sobretudo, porque nós víamos e queríamos ver-nos refletidos tal como o outro. Dessa forma, as mulheres burguesas dos livros de Alencar, por exemplo, vestem-se à francesa não porque quiséssemos inserir a moda francesa em nossas obras, ou porque quiséssemos copiá-las, mas porque as brasileiras da não-ficção vestiam-se, ainda que o Rio de Janeiro possuísse - e possui - um calor escaldante, com os tecidos e as rendas francesas. Logo, o universo dissonante representado que víamos na literatura era reflexo da estrutura cultural local.

Para livrarmo-nos do espírito do outro, a nossa única saída era tentarmos ser inéditos, produzir algo totalmente novo; a inserção do modelo dos fantasmas, mesmo que diversificada, era considerada cópia, ou seja, era mal vista pelos intelectuais. Schwarz esclarece que ela possuía valor secundário em relação ao original, valia menos: tínhamos de criar, portanto, a partir do nada. Esse culto pelo novo e, ao mesmo tempo, culto ao europeu, provocou em nossos intelectuais um sentimento de mal-estar, pois conseguíamos, e certamente não queríamos, renunciar aos empréstimos. Vale aqui lembrar que Marx afirmava que o espelho das colônias era os países mais adiantados, logo, a Europa; hoje, refletimo-nos sobretudo a partir da imagem dos Estados Unidos. Para a atual classe média - se é que essa categoria ainda dá conta de alguma coisa -, o McDonald's é quase brasileiro. 
A cópia, para o crítico, é vista como o pecado original, a causa da desconexão; no entanto, é importante ressaltar que esse descompasso é característica formadora de nossa identidade. Sílvio Romero apontara que, enquanto a elite dedicava-se a copiar a cultura do Velho Mundo, a maior parte da população mantinha-se analfabeta, ou seja, essa elite era capaz de pensar sobre o outro, mas era incapaz de refletir sobre a sua realidade local. 'Reflexão' é, deste modo, uma das palavras-chave do ensaio de Schwarz, uma vez que ainda falta a nossos intelectuais de hoje e aos artistas brasileiros de todos os tempos aprofundar a reflexão e, para isso, a história, evidentemente, não pode ser abolida; começar do novo seria, portanto, queimar as etapas já percorridas no passado.

O caráter inautêntico tornou-se, de acordo com o mesmo ensaísta, a marca ubíqua de inautenticidade, o penhor de nossa formação. Queríamos renovar, mas não entendíamos que renovação não significava romper com toda a experiência acumulada até então, como podemos inferir tanto no ensaio de Gullar quanto no de Schwarz. Dessa forma, desejávamos criar uma literatura ou arte nacional brasileira, mas não compreendíamos que o caráter de nossa arte deveria ser organizado como em um caleidoscópio, unindo-se os fragmentos de diferentes maneiras a cada movimento que se faria no cone. Tropicalista ou antropofágico, o caráter nacional seria aquele que não negaria o outro, mas o assimilaria a partir de um exercício reflexivo. E é esse exercício que falta aos intelectuais brasileiros, conforme aponta Schwarz, pois eles apaixonam-se, de tempos em tempos, por novas teorias, mudando, como os políticos, de partido ao seu bel-prazer: café da manhã estruturalismo, almoço marxismo e, à noite, teoria da recepção.

O elemento nacionalista é relido pelo movimento antropofágico a partir da teoria da aglutinação. Gullar acredita que esse seja um movimento bastante elaborado, pois afirma que quando nos referimos à cultura brasileira:

Não se trata, evidentemente, de uma cultura própria, especificamente nacional, mas cultura brasileira no sentido de aglutinação dinâmica de elementos reelaborados que, através das décadas, se mantêm ligados e ativos numa interação capaz de responder ao presente e ajudar na sua formação (GULLAR, 1978, p. 46).

Para Schwarz, entretanto, a Antropofagia é vista como uma tentativa de interpretar triunfalmente o nosso atraso e, com isso, ela visaria a queimar uma etapa, pois ainda não refletiria sobre os desajustes da sociedade, e - o que é mais grave - tal atitude não é vislumbrada como vexame, mas com otimismo. Lúcia Helena (1994), em ensaio sobre os modernistas de 22, afirma que os participantes apresentariam uma posição ingênua em relação às vanguardas, não demonstrando reflexão sobre elas, não compreendendo as diferenças que existiriam entre a vanguarda em um país desenvolvido e em um país subdesenvolvido. $\mathrm{O}$ 
movimento de auto-estima modernista é analisado por Gullar como a expressão de confiança de que o Brasil estaria abrindo os seus próprios caminhos; para Schwarz, entretanto, ele é um processo digestivo sem culpa e acrítico.

$\mathrm{Na}$ Antropofagia, tínhamos que devorar los hombres, ou seja, alimentar-nos das vanguardas. Esclarece Gullar no artigo Vanguarda e subdesenvolvimento que, em um país subdesenvolvido, a verdadeira vanguarda artística é aquela que "buscando o novo, busca a libertação do homem, a partir de sua situação concreta, internacional e nacional" (GULLAR, 1978, p. 24). A questão do novo, em um país subdesenvolvido, é vital porque denota transformação, ou seja, é uma exigência para aqueles que vivem em uma sociedade dominada pela miséria, sobretudo quando se sabe que essa miséria é produto de estruturas arcaicas, compreende-se assim o caráter otimista de Oswald de Andrade.

A apreensão do elemento nacional, em um país com uma cultura tão diversa como a nossa, dar-se-á conforme Argumentação contra a morte da obra de arte ${ }^{1}$, a partir das manifestações "folclóricas, popularescas, já meramente artesanais e esclerosadas, até as manifestações artisticamente consagradas, às vezes de alto nível estético, às vezes não, da cultura urbana mais dinâmica e contemporânea" (GULLAR, 1993, p. 85).

É importante, portanto, acumular a experiência das diferentes manifestações regionais de todo o país para podermos abarcar alguns dos aspectos que formam o sentimento nacionalista em um país subdesenvolvido, multifacetado e latino-americano para, assim, observar as suas mudanças, como podemos observar nas palavras de Valèry: "Beau ciel, vrai ciel, regardez-moi, qui change", ou seja, se tudo está em constante mudança, por que o caráter nacional da obra de arte tem de manter-se estanque?

A procura pelo novo é uma questão fundamental para os países subdesenvolvidos porque denota transformação. Quando assimilávamos as vanguardas européias em diferentes momentos da nossa história cultural não nos dávamos conta de nosso subdesenvolvimento, porque acreditávamos que o que nos diferenciava da Europa era uma porção de tempo; assim, críamos que seríamos como os europeus após alguns séculos: eles eram o nosso futuro, eles eram o espelho de nosso destino.

Falar de vanguarda em um país subdesenvolvido e em um país desenvolvido é, portanto, distinto, pois, para os países desenvolvidos, a vanguarda é um instrumento de renovação de estruturas arcaicas; já para os subdesenvolvidos ela funciona como ferramenta de esperança, ou seja, é uma tentativa de libertar-se, de reverter a ordem vigente. Assim

${ }^{1}$ Quando me refiro a Schwarz, neste artigo, é importante esclarecer que me centro em SCHWARZ, Roberto. Nacional por subtração. In: Cultura e política: 1964 - 1969. São Paulo: Paz e Terra, 2001. 
sendo, a má-formação brasileira, de acordo com Schwarz, é o resultado de um disparate que se organiza a partir de uma posição insustentável conferida à cultura nacional: a aceitação ou não da vanguarda, a produção ou não de cópias. Logo, tornávamo-nos incapazes de enxergar o que havia de original no imitado.

Ferreira Gullar nos explica que é evidente que a arte tem de visar a uma superação da singularidade nacional, o que não se verifica, por exemplo, quando um artista se limita a retratar os aspectos exóticos da realidade nacional, concepção já apresentada por Machado de Assis em Instinto de nacionalidade. Para sobrepujar, portanto, a exigência da própria superação artística, temos de suplantar o universal no particular e será a partir do conhecimento do outro que iremos conhecer a nós mesmos. De acordo com Friedrich Schlegel: "Não existe autoconhecimento que não seja histórico. Ninguém se conhece a si mesmo, quando não conhece seus camaradas sobretudo o mestre dos mestres, o gênio da época" (SCHLEGEL, 1991, p. 43-44).

A arte de um país subdesenvolvido é aquela que buscará exprimir a sua universalidade a partir da sua particularidade, das suas contradições e da originalidade das suas cópias, como é o caso do índio de Alencar, baseado em Rousseau, pois ele não é cópia de nenhum romance europeu. As especificidades da arte de um país subdesenvolvido contribuirão, sem dúvida, para a representação das particularidades de um povo, e nenhuma outra arte poderá exprimilas.

Gullar alerta que, para não cairmos na mitificação do nacionalismo, temos de apresentar as tensões que existem em nosso território, ou seja, a contradição entre as zonas desenvolvidas e as zonas subdesenvolvidas, entre a cidade e o campo, entre as lutas de classes. Não podemos hoje ainda discutir ou procurar definir o elemento nacional como se ele fosse uma caixa de Pandora, algo que poderia modificar toda a estrutura então atual vigente e revelar, talvez, a verdade sobre a nossa identidade como algo único e puro.

Tanto Schwarz como Gullar nos auxiliam a compreender os tons dissonantes que estão imersos em nossa história literária com respeito (para não repetir "relação") ao mal-estar que envolvia a nossa relação com a cópia e com as vanguardas, assim como a busca pelo caráter nacional e a não-compreensão, por vezes, da condição de país subdesenvolvido, cerne para a iluminação das questões anteriores. O que interessa para os críticos, portanto, é fugir das tentativas claustrofóbicas de definir o caráter nacional como se possuíssemos uma unidade cultural, como se não fôssemos o campo e a cidade, o Nordeste e o Rio Grande do Sul - ou São Paulo e o Rio Grande do Sul -, os Modernistas e os Tropicalistas, como se não fôssemos, portanto, fragmentados, dissonantes e dialeticamente disparatados. 
A compreensão do elemento nacional é um processo cumulativo e dinâmico. Para afinarmos o tom, temos de compreender que buscar uma arte estritamente nacional é alimentar preconceitos em relação à arte brasileira e colocá-la em um universo reducionista e limitador, pois não corresponderia à realidade, não fundiria os elementos contraditórios da cultura e, não a expressando, o objeto analisado deixaria de ser arte, tornando-se, portanto, atividade alienante e estéril.

\section{Referências}

ASSIS, Machado. Notícia da atual literatura brasileira: instinto de nacionalidade. In: CANDIDO, Antonio e CASTELLO, J. Aderaldo. Presença da Literatura Brasileira: das origens ao realismo. São Paulo: Bertrand Brasil, 1994. p. 301-304. 1975.

Formação da Literatura Brasileira: momentos decisivos. Belo Horizonte: Itatiaia,

GULLAR, Ferreira. Argumentação contra a morte da arte. Rio de Janeiro: Revan, 1993.

. Vanguarda e subdesenvolvimento. Rio de Janeiro: Civilização Brasileira, 1978.

HELENA, Lúcia. A semana de 22, ontem e hoje. Letras de Hoje. Porto Alegre, n. 97, set. de 1994.

SCHLEGEL. Friedrich. Fragmentos de Idéias In: CHAMPI, Irlemar (Coord.). Fundadores da modernidade. São Paulo: Ática, 1991.

SCHWARZ, Roberto. Nacional por subtração In: Cultura e política: $1964-1969$.

São Paulo: Paz e Terra, 2001. 